\title{
PENGARUH SANITASI HYGIENE DI AREA RESTORAN \& MAIN KITCHEN TERHADAP KEPUASAN TAMU DI HARRIS HOTEL \& CONVENTIONS MALANG
}

\author{
Ela Agustina ${ }^{1}$ \\ Dewi Hermin Sutanto ${ }^{2}$ \\ Program Diploma Kepariwisataan Universitas Merdeka Malang1 \\ Jl. Bandung No. 1 Malang
}

Korespodensi dengan Penulis:

Dewi Hermin S: Telp: 628123593185

E-mail: shienny_petra@yahoo.com

\begin{abstract}
The purpose of this research is to provides an overview of the influence of sanitation hygiene in the restaurant area and main kitchen toward guest satisfaction. The purpose this research is to know the influence of sanitation and hygiene in the restaurant area and main kitchen. Research methodology used in this research was descriptive qualitative. Data analysis technique include data collection, data reduction, data presentation and conclusion. The result obtained from this research is hygiene sanitation condition in the restaurant area and main kitchen that fulfilled the requirement can give guests satisfaction. The qualified hygiene sanitation be able to support employees perfomance at the main kitchen. Sanitation and hygiene are very important to the development of a hotel especially in provide security and comfort and health to the various guest.
\end{abstract}

Keywords : Sanitation Hygiene, Main Kitchen, Restaurant

Pariwisata merupakan salah satu sektor menjadikan sektor pariwisata sebagai penghasil devisa Negara terbesar unsur yang dikembangkan pemerintah disamping sektor migas. Hal ini dalam menyokong pembangunan 
nasional. Berkaitan dengan hal tersebut pemerintah Indonesia melalui Departemen Pariwisata dan Budaya berusaha untuk meningkatkan pembangunan dan pengembangan sektor pariwisata untuk menghasilkan dan meningkatkan devisa Negara, memperluas lapangan kerja dan memasarkan produk nasional.Sarana dan prasarana yang memadai dan berkualitas akan memberikan hasil yang diharapkan dalam mengembangkan pariwisata beserta hasil-hasilnya. Diantaranya adalah hotel beserta fasilitasnya yang tersedia untuk melayani wisatawan yang melakukan perjalanan untuk berwisata. Layanan hotel yang baik selain kamar adalah restaurant, dimana pengolahan makanan yang diproduksi bagian kitchen menjadi daya tarik tersendiri bagi tamu dalam menikmati menu yang disajikan. Mengembangkan sektor pariwisata melalui dunia perhotelan tidak akan berhasil tanpa didikung oleh sumber daya manusia perhotelan yang berkualitas. Salah satu kendala yang sering dihadapi pada dunia perhotelan adalah mendapatkan sumber daya manusia yang memiliki kualifikasi yang baik dibidangnya (profesional).
Sanitasi menurut Dr.Azrul Azwar, MPH (2000:4) merupakan cara pengawasan terhadap berbagai faktor lingkungan yang mungkin mempengaruhi derajat kesehatan masyarakat sedangkan Hygiene menurut Brownell ( R.Sihite.2000:3 ) bagaimana caranya orang memelihara dan melindungi kesehatan.

Hotel sebagai salah satu sarana akomodasi bagi wisatawan harus dapat menyediakan fasilitas yang memadai untuk kepentingan dan kepuasan tamu. Diperlukan adanya kerja sama yang baik antar departemen dalam satu hotel untuk meningkatkan pelayanan tamu. F \& B Produk merupakan departemen yang menyediakan makanan dan minuman yang dibutuhkan tamu sehingga hygiene and sanitasi harus diperhatikan untuk menjaga kesehatan bagi para tamu. Main kitchen sebagai bagian dari Food \& Beverage produk pada hotel memiliki peranan yang sangat penting dalam menyediakan makanan mulai dari bahan mentah sampai menjadi makanan siap saji. Guna menjaga kesehatan para tamu maka main kitchen harus selalu menjaga kebersihan dan kesehatan di lingkungan kitchen mulai dari kebersihan peralatan, bahan 
makanan, maupun para pengolah makanan itu sendiri sebelum memulai memproduksi bahan makanan tersebut.

\section{METODE}

Jenis penelitian ini adalah penelitian deskriptif dengan pendekatan kualitatif . Penelitian ini bertujuan untuk membuat deskripsi atas suatu keadaan hygiene sanitasi di Harris Hotel \& Coventions Malang secara sistematis, faktual dan akurat.

1. Sanitasi dan hygiene $(\mathrm{x})$

Sanitasi : Usaha kesehatan prevenif yang menitik beratkan kegiatan kepada usaha kesehatan lingkungan hidup manusia.

Hygine : Usaha kesehatan preventif yang menitik beratkan kegiatannya kepada usaha kesehatan individu, maupun usaha kesehatan pribadi hidup manusia

2. Kepuasan tamu (y)

Menurut Kotler dan Armstrong (2001:9) Kepuasan konsumen adalah sejauh mana anggapan kinerja produk memenuhi harapan pembeli. Bila kinerja produk lebih rendah ketimbang harapan pelanggan, maka pembelinya merasa puas atau amat gembira.

\section{Adapun ruang lingkup} permasalahan yang akan dibahas dalam penelitian ini yaitu Pengaruh sanitasi hygiene di area restoran \& main kitchen terhadap kepuasan tamu di Harris Hotel \& Conventions Malang.

Metode pengumpulan data yang penulis gunakan sebagai rujukan dalam penyusunan karya tulis ilmiah ini adalah :

1. Survei Lapangan (Field research)

Dalam survei penulis melakukan dengan langsung mendatangi objek penelitian untuk mendapatkan data dan informasi yang di perlukan oleh penulis.

2. Wawancara (Interview)

Yaitu mendatangi langsung pimpinan dan karyawan hotel tersebut dengan megadakan tanya jawab terhadap objek yang di teliti.

3. Pengamatan (Observasi)

Yaitu penulis mengadakan pengamatan langsung ke objek yang di teliti untuk memperoleh gambaran yang sebenarnya. 
4. Dokumentasi

Metode dokumentasi

(Documentation)Yaitu pengumpulan

data yang dilakukan dengan cara

mencatat dari semua dokumen-

dokumen yang berhubungan dengan

permasalahan yang nantinya

memperkuat dalam penulisan laporan

5. Studi Kepustakaan (Library Research)

Yaitu pengumpulan data yang penulis lakukan dengan jalan mempelajari buku - buku serta sumber data lainya yang ada hubunganya dengan judul penelitian ini.

Sumber data yang di gunakan dalam penulisan ini adalah :

1. Data Primer

Yaitu data yang dikumpulkan sendiri oleh perorangan atau organisasi melalui objeknya. Data primer di peroleh dari karywan bagian restoran dari pengunjung

2. Data Sekunder

Yaitu data yang diperoleh dalam bentuk sudah jadi yang berupa publikasi atau data yang dikumpulkan pihak lain. Data sekunder di peroleh dari studi kepustakaan.
Teknik analisis data yang digunakan pada penelitian ini yaitu:

1. Pengumpulan data adalah alat bantu yang dipilih dan digunakan oleh peneliti dalam kegiatannya mengumpulkan agar kegiatan tersebut menjadi sistematis dan dipermudah olehnya.

2. Reduksi data adalah proses pemilihan, pemusatan, perhatian pada penyederhanaan, dan transformasi data "kasar" yang muncul dari catatan-catatan tertulis di lapangan.

3. Penyajian data adalah merupakan salah satu kegiatan dalam pembuatan laporan hasil peneliti yang telah dilakukan agar dapat dipahami dan dianalisis sesuai dengan tujuan yang diinginkan.

4. Penarikan kesimpulan adalah bagaimana awal pengupulan data, peneliti sudah harus memahami apa arti dari berbagai hal yang ditemukan dengan mulai melakukan pencatatan pola-pola sistematis penelitian, data wawancara yang telah didapatkan dari beberapa informasi . 
HASIL

Bedasarkan penelitian yang telah di lakukan di Harris Hotel \& Coventions maka dapat dijabarkan bahwa kondisi di Main Kitchen yaitu 1) senantiasa dalam keadaan bersih, 2) mempunyai cukup persedian air bersih untuk mencuci bahan makanan dan memasak, 3) memiliki tempat sampah yang cukup, 4) alat-alat dapur yang selalu dalam kondisi bersih, 5) memiliki sarana yang lengkap, 6) memiliki ventilasi dan penerangan yang cukup, 7) memiliki tempat penyimpanan yang baik dan 8 ) memliki system sirkulasi udara yang cukup.

Penelitian yang telah di lakukan di area restoran yaitu 1) memiliki sarana yang luas memadai, 2) mempunyai perlengkapan yang baik, 3) mempunyai peralatan seperti chinaware, cutleries dan glassware dalam kondisi bersih, 4) memiliki ventilasi dan penerangan yang cukup, 5) memiliki tempat yang nyaman dan bersih dan 6) memiliki tempat penyimpanan yang cukup.

\section{PEMBAHASAN}

Kondisi sanitasi hygiene di Harris Hotel \& Coventions sudah cukup baik. hal ini didasarkan pada hasil penelitian yang sudah dlakukan oleh peneliti . sanitasi hygiene yang memenuhi syarat dapat menunjang kinerja karyawan di bagaian main kitchen.

Agar sanitasi dapat berjalan lancar, diperlukan berbagai sistem untuk pelaksanaannya. Baik hygiene maupun sanitasi sudah tentu harus ditanamkan pada karyawan agar dilaksanakan secara konsisten sehingga mutu produk dan service hotel atau restoran , khususnya bagi para konsumen yang sangat peka terhadap masalah-masalah tersebut.

Menurut Khasanah (2013) tiga aspek sanitasi hygiene yang harus dikuasai diantaranya : 1) adanya sikap kritis konsumen yang makin meningkat, 2) pada umumnya owner atau manajemen menuntut hal yang serupa pada karyawannya, 3) karyawan pun membutuhkan tingkat kesehatan dan keselamatan kerja.Selama ini, nampaknya pengertian hygiene dan sanitasi masih sering dibaurkan begitu saja. Mungkin di karenakan sangat dekatnya kaitan dua istilah tersebut dalam praktik sehari-hari. Tiga perbedaan dan pemakaiannya. Demi tercapainya kondisi higienis tersebut, diharapkan akan tercapai kenyamanan hidup, keamanan pada waktu makan, 
kesehatan alat makan, dan bebasnya manusia dari bahaya-bahaya keracunan makanan. Kondisi ini harus dipertahankan secara terus-menerus, dikontrol, dievaluasi, dan dibuat sedemikian rupa sehingga tetap pada tingkat kualitas tertentu.

Dalam penerapan sanitasi dan hygiene terdapat tiga aspek penting yaitu (a) aspek Kesehatan diantaranya mencegah berkembangnya penyakit menular, mencegah timbulnya penyakit akibat kerja, menjaga kebersihan di area restoran dan mencegah terjadinya kecelakaan, (b) aspek Estetika diantaranya mencegah timbulnya tempat-tempat yang kotor, mencegah pemandangan yang kurang sedap di sekitar hotel dan di area restoran, mencegah timbulnya bau-bau yang tidak sedap dan meningkatkan rasa kenyamanan dalam bekerja, (c) aspek bisnis operasional diantaranya menarik minat tamu untuk berkunjung ke hotel, minimal hanya makan dan minum di restoran, merupakan sarana promosi yang ampuh Meningkatakan kesejahteraan karyawan, memberikan pelayanan yang memuaskan kepada tamu.

Bagi sebuah industri perhotelan, sanitasi perhotelan mempunyai dua peranan pokok yaitu 1) peranan fisik yaitu menjamin kebersihan lingkungan umum hotel, adapun yang dimaksud dengan kebersihan tidak hanya terbatas pada kebersihan saja, akan tetapi kebersihan fisik hotel secara keseluruhan yaitu meliputi kebersihan airnya, kebersihan makan dan minumnya, kamarnya, toilet dan dapurnya serta kebersihan peralatan dan bersih dan bebas dari insekta/serangga dan tikus yang dapat mengganggu kesehatan dan 2) peranan psykologis yaitu menjamin kepuasan terhadap para tamunya serta karyawannya dalam hal istirahat, kesenangan dan kegembiraan, keamanan, perlindungan dan kebebasan/privasi Adapun manfaat sanitasi hygiene bagi Harris Hotel \& Coventions yang meliputi 1) hidup lebih disiplin dalam kerja dan hasil, 2) selalu menjaga kebersihan diri dan lingkungan, 3) hidup sehat dan lebih percaya diri, 4) hidup penuh arti untuk orang lain, 5) membuat nyaman dan aman, 6) menjamin tempat kerja yang bersih, 7) mencegah timbulnya penyakit menular dan 8) mencegah kecelakaan dalam bekerja. 
Kondisi sanitasi hygiene di area restoran cukup baik, hal ini didasarkan fakta-fakta hasil penelitian. Sanitasi hygiene yang cukup baik tentu saaja dapat membuat pelanggan puas menurut Kotler dan Susanto (2000:52) kepuasan pelanggan adalah sejauh mana anggapan kinerja produk memenuhi harapan pelanggan. Bila yang diterima sama atau lebih dari harapannya maka pelanggan akan kecewa, sebaliknya bila yang diterima sama atau lebih dn harapannya maka pelanggan akan puas, gembira atau senang.

Tujuan sanitasi dan hygiene di area restoran yaitu 1) menerapakan Sanitasi dan Hygiene pada karyawan, area dapur, area restoran agar setiap produk yang di hasilkan bersih, sehat, dan berkualitas, 2) menciptakan suasana aman, nyaman bagi para konsumen, 3) mengupayakan area restoran, peralatan cutleries, chinaware,glassware dll terpelihara kebersihanya, 4) menciptakan suasana kerja yang asri dan sehat dan 5) mencegah timbulnya masalah gangguan kesehatan pada karyawan .

Manfaat dari kepuasan pelanggan yaitu 1) hubungan antara perusahaan dan para pelanggan menjadi harmonis, 2) memberikan dasar yang baik untuk pembelian ulang, 3) membentuk suatu rekomendasi dari mulut ke mulut yang mengutungkan bagi hotel, 4) dapat menciptakan loyalitas pelanggan, 5) reputasi perusahaan menjadi baik di mata pelanggan dan 6) laba yang di peroleh meningkat.

\section{KESIMPULAN}

1. Sanitasi dan Hygiene sangat penting bagi perkembangan sebuah hotel khususnya dalam memberikan keamanan dan kenyamanan serta kesehatan tamu dari berbagai hal yang tidak diinginkan melalui kesehatan dan kebersihan makanana dan minuman, peralatan makanan yang di sajikan ke pada tamu.

2. Penerapan standar operasional procedure safety and hygiene regulations in preparating lebih di tingkatkan sehingga kontrol atau pengawasan dalam prosedur standar yang telah ditetapkan dapat terus berjalan demi tercapainya visi-misi hotel. 


\section{DAFTAR PUSTAKA}

Anonimous, 2014. Pentingnya Penerapan

Hygiene Sanitasi

(Online123dok.com/document /2014-pentingya penerapan

hygiene sanitasi.html). Diaskes tanggal 8 juli 2016.

Bayu, Made. 2010. Pengaruh

Kepuasan.(online.blogspot.co.id /06/pengaruh-kepusan.html). Diakses tanggal 6 juli 2016.
Gagaje, 2013. Pengertian Sanitasi

(online.blogspot.co.id/2013/05 /pengertian-sanitasi-dan hygiene.html). Diaskes tanggal 8 juli 2016.

Noval, Muhammad. 2010. Pengertian Sanitasi Hygiene. (online.blogspot.co.id/8/penge rtian-sanitasidanhygiene.html). Diakses tanggal 6 Juli 2016. 